\title{
Distribution of Fasciola bepatica in Swedish dairy cattle and associations with pasture management factors
}

\author{
Adam Novobilský1, Sofia Sollenberg'1, Johan Höglund ${ }^{1}$ \\ ${ }^{1}$ Section for Parasitology, Department of Biomedical Sciences and Veterinary Public Health, Swedish University \\ of Agricultural Sciences (SLU), Uppsala, Sweden
}

\begin{abstract}
The geographic distribution of Fasciola hepatica infection in relation to management routines was studied in Swedish dairy herds by testing for F. hepatica antibodies with the enzyme-linked immunosorbent assay (ELISA). In addition, all farmers were sent a questionnaire asking for information about type of production, management routines and historical record of F. hepatica at slaughter. A total of 176 farmers (41\%) responded to the questionnaire. A total of 426 bulk tank milk (BTM) samples were randomly selected from the period September to October 2012 representing approximately $10 \%$ of all herds in Sweden. The overall seroprevalence was $25 \%(\mathrm{n}=107 ; 95 \%$ confidence interval $=21-29 \%)$ with a concentration of herds located in south-western Sweden. Among the seropositive herds, $31(29 \%)$ had antibody levels indicating production loss. There were no significant differences in seropositivity between organic and conventional herds or due to pasture management routines. The length of grazing period, which increased the risk for heifers, was found to be the most influential factor. A discrepancy was noted between reported F. hepatica presence at meat inspection and herds that were seropositive based on BTM-ELISA results. Although the largest proportion of seropositive BTM samples $(80 \%)$ came from herds where liver fluke presence had been observed at meat inspection after slaughter, seropositive BTM samples were also diagnosed in five herds $(17 \%)$ with no remarks at slaughter. In conclusion, F. hepatica is a common parasite in Swedish dairy herds and the month of heifer turn-out and the grazing period length were the most influential factors observed.
\end{abstract}

Keywords: fasciolosis, ELISA, meat inspection, geographical information systems, Sweden.

\section{Introduction}

Liver fluke (Fasciola hepatica) is the causative agent of a production-limiting parasitic disease, fasciolosis, affecting livestock worldwide. The economic impact of fasciolosis has been shown with respect to sheep, beef and dairy cattle production. In the European Union, financial losses in ruminant production due to F. hepatica were recently estimated at $€ 1100-2000$ million per annum, with the highest economic impact in dairy production (Anonymous, 2012).

Fasciolosis occurs mainly as a subclinical disease in dairy cattle, but in highly affected herds it reduces milk yield and quality (Mezo et al., 2011; Charlier et al., 2014). It has been shown that significant production losses occur in herds with a prevalence of $F$. hepatica infection of $25 \%$ or higher (Vercruysse and Claerebout, 2001). Detection of antibodies to liver fluke by the enzyme-linked immunosorbent assay

Corresponding author:

Adam Novobilský

Section for Parasitology

Department of Biomedical Sciences and Veterinary Public Health

Swedish University of Agricultural Sciences (SLU)

Box 7036, 75007 Uppsala, Sweden

Tel. +46 1867-2381; Fax +46 1867-3334

E-mail: adam.novobilsky@slu.se
(ELISA) in bulk tank milk (BTM) samples (Duscher et al., 2011) is currently the most common method for F. hepatica diagnosis in dairy production at the herd level (Forbes and Charlier, 2006; Charlier et al., 2007, 2011, 2014; Salimi-Bejestani et al., 2007; Bennema et al., 2009). The simplicity of BTM collection provides an easy tool for spatial liver fluke screening at different regional scales. Although the sensitivity of BTMELISA is considered to be lower than that of ELISA based on serum and/or individual milk samples (Duscher et al., 2011), a high positive correlation between F. hepatica-specific BTM antibody levels and herd seroprevalence has been demonstrated (SalimiBejestani et al., 2005). Minimum in-herd prevalence in flocks for F. hepatica antibodies to be detectable in BTM samples varies from $20 \%$ to $60 \%$ (Reichel et al., 2005; Salimi-Bejestani et al., 2005; Duscher et al., 2011).

In Sweden, dairy cattle are the most important livestock commodity in the agriculture sector. In 2012, the total number of cattle in Sweden was approximately 1.5 million, including 348,000 dairy cows distributed between approximately 4,500 herds and with an average herd size of about 80 cows (Swedish Board of Agriculture, 2012). According to meat inspection data, the prevalence of F. hepatica in Swedish cattle has increased in the past decade (König and Welling, 
2013). Based on a discrepancy we observed earlier between meat inspection data and F. hepatica seroprevalence in beef, we speculated that dairy cattle are similarily affected as beef cattle in Sweden (Novobilský et al., submitted). Seroprevalence in 210 Swedish dairy herds in south-central Sweden was 7\% in 2008 and no significant differences between organic and conventional herds were observed (Höglund et al., 2010). However, to date no systematic nationwide survey has been performed and risk factors have not been identified. In a study in Belgium, mowing of pasture, length of grazing season, proportion of grass in the diet and herd size were found to be associated with a higher risk of infection (Bennema et al., 2011). Pasture management has also been suggested as the most crucial factor affecting the risk of Fasciola infection in Sweden, with cows grazing on grass leys being less affected than beef cattle that often graze marginal natural pastures.

The aim of this study was to investigate the spatial distribution of $F$. hepatica infection in Swedish dairy herds based on BTM-ELISA, and to explore the relationship between risk of exposure to $F$. hepatica and management factors in Sweden.

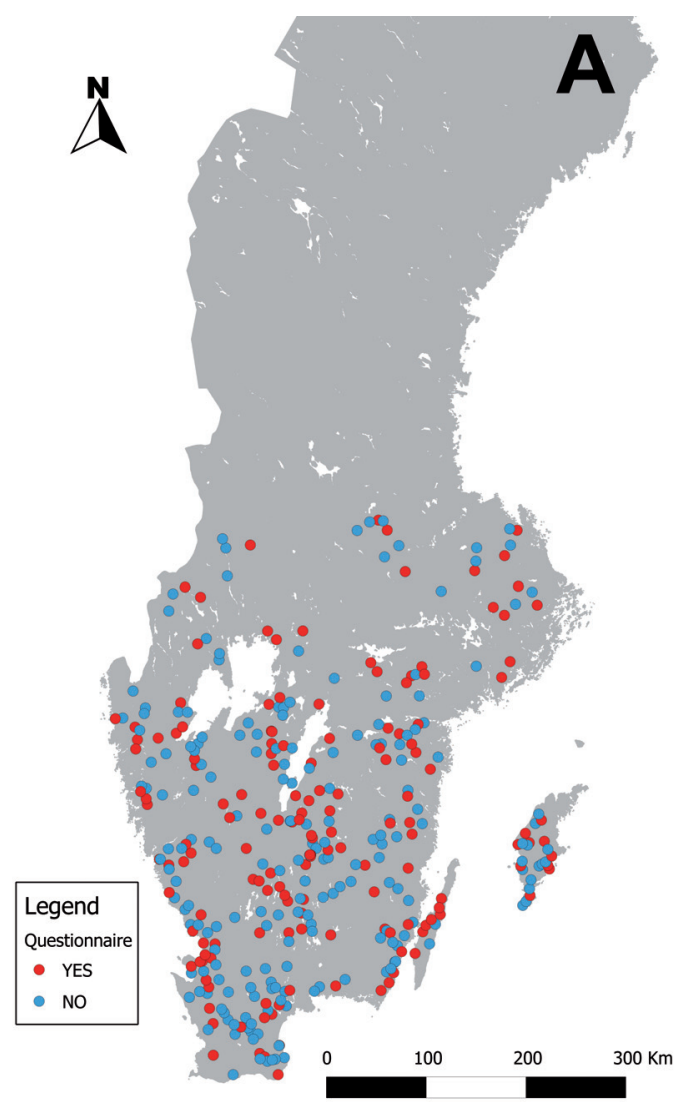

\section{Material and methods}

\section{Milk samples}

BTM samples were collected in September and October 2012 by a technician at the Eurofins (http:// www.eurofins.se/) laboratory in Jönköping, Sweden. The technician randomly selected $10 \%$ of samples per county, which produced BTM from 426 farms, at that time representing $8.6 \%$ of all dairy herds in Sweden $(\mathrm{n}=4,968)$ (Swedish Board of Agriculture, 2012). As $82 \%$ of total milk production in Sweden is concentrated to the southern part of the country (Swedish Board of Agriculture, 2012), sampling was restricted to this area (Fig. 1). Milk samples were collected in special tubes pre-treated with bronopol as a preservative. Upon arrival at the laboratory, fat was removed from the milk by centrifugation $(16,000 \mathrm{~g}$ for $5 \mathrm{~min})$ and the samples were stored at $-20^{\circ} \mathrm{C}$ before being analysed.

\section{Antibodies in milk}

F. hepatica antibodies were measured in BTM using the SVANOVIR ${ }^{\circledR}$ F. hepatica-Ab ELISA test (Boeringer,

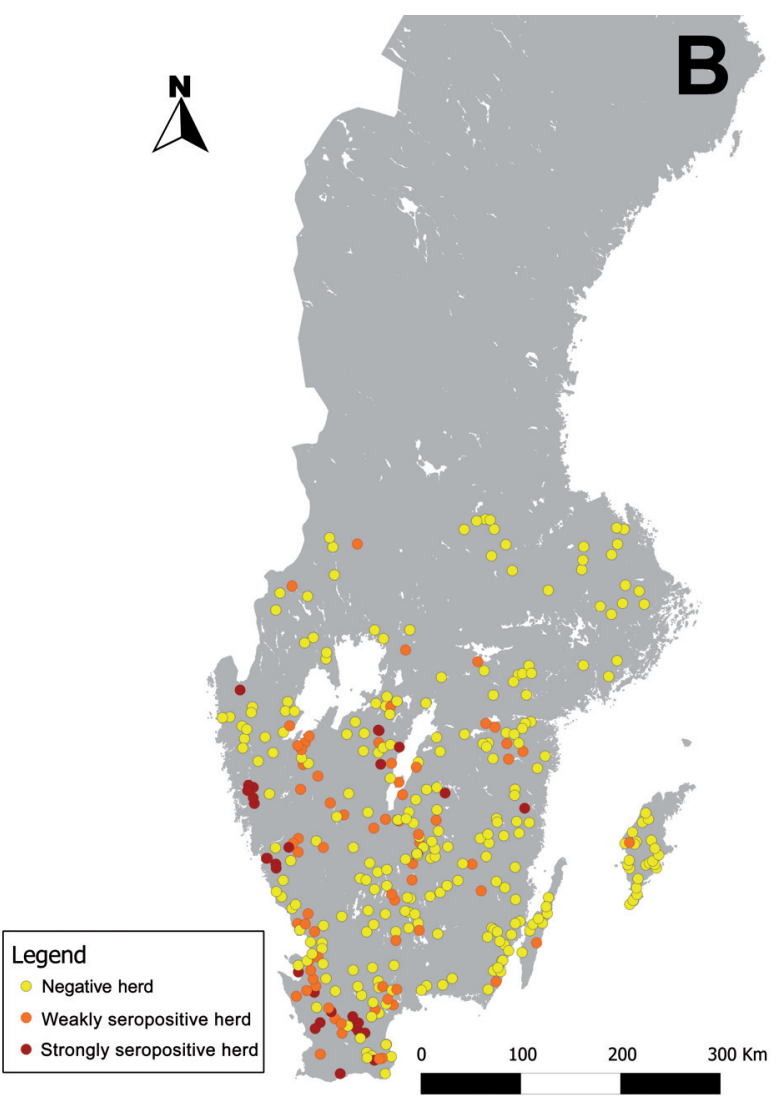

Fig. 1. Distribution of all Swedish herds studied $(n=426)$ including herds for which there was a questionnaire response $(n=176)$ (A) and the distribution of F. hepatica-seropositive dairy herds in Sweden (B). 
Uppsala, Sweden). This commercial ELISA kit, where antibodies to $F$. hepatica are detected based on purified excretory/secretory proteins prepared from crude parasite extracts, and validated for economic thresholds under Belgian conditions using milk samples from naturally infected populations (Charlier et al., 2007). The results were expressed as the ratio between the optical density of the sample investigated and that of positive controls included on each plate. The cut-off was set at 0.3 meaning that ratios below this level were deemed negative; 0.3-0.6 indicating contact with liver fluke but no interference with production; and $\geq 0.6$ clearly consistent with fluke infection most likely associated with production loss (Vercruysse and Claerebout, 2001; Charlier et al., 2007).

\section{Questionnaire}

In February 2013, a package containing a cover letter and a questionnaire was posted to all farms from which we received BTM, but without information on measured exposure to F. hepatica in their herds (Fig. $1)$. The cover letter described the background and the purpose of the study, assured anonymity of those responding and provided guidance regarding the terminology used and how to complete the questionnaire. We also offered a free diagnostic sample to motivate farmers to respond. Farmers who did not respond were reminded by additional e-mail messages once or a maximum of twice.

The questionnaire was divided into three sections, each comprising between 3 and 12 questions and with 27 in the form of multiple-choice (MC) alternatives and three in the form of sentences where the number of animals or kilograms of milk had to be inserted into blank spaces. The questions concerned: farm and herd size, milk production, dates of turn-out and housing, type and area of pasture grazed by heifers and cows, and abattoir reports on the presence of parasitic diseases. The MC questions contained provided 4-6 alternatives and always included "do not know" as one. Information was also gathered about grazing routines and in particular, parasite control methods employed during the three previous grazing seasons. Before the study, the procedure was tested on 10 farmers and amended whenever ambiguity was detected. Factors recorded in the questionnaires are summarised in Table 1 .

Table 1. Management practices on dairy farms according to questionnaire responses.

\begin{tabular}{ll}
\hline Management factor & Value type (categories) \\
\hline A) Number of animals and herd type & \\
\hline Number of dairy & Scale \\
Number of beef & Scale \\
Organic or conventional & Nominal (organic; conventional) \\
Robotic milking & Nominal (yes, no) \\
Use of pastures & Nominal (cultivated; both cultivated and natural) \\
Grazing pattern & Nominal (contact of cows with calves, heifers, sheep) \\
\hline B) Specific questions about cows and heifers & \\
\hline Outdoor access & Nominal (housed; paddock with; or without grass; pasture) \\
Daily grazing time during summer months & Ordinal (24 h; $\geq 6 ; \leq 6$ h) \\
Month of turn-out & Date (April; May; June) \\
Month of housing & Date (September; October; November) \\
Length of grazing period (months) & Scale \\
Grazing pattern in previous year & Nominal (cows only; cows+heifers+calves; heifers+calves) \\
Stocking density & Nominal ( $<5 ; 5-10 ;>10$ animals per Ha) \\
Mowing of pasture & Nominal (yes $50-100 \%$ partly $\leq 50 \%$ no) \\
Amount of grass in the diet & Nominal (grass only; $\geq 50 \% ;<50 \%$ other) \\
Deworming routines & Nominal (no; yes-due parasites; yes-prophylaxis) \\
\hline C) Welfare and production & \\
\hline Milk production ECM in 2011 & Scale \\
Effects on the milk production reduced & Nominal (reduced production; during first two weeks on pasture; reduction in \\
Parasites recorded at slaughter & the middle of grazing season; no reduction; do not know) \\
& Nominal (unknown; no record; liver flukes; liver damage; both liver flukes and \\
\hline
\end{tabular}

$(\mathrm{ECM}=$ energy-corrected milk) 


\section{Data management and statistical analyses}

All herds were located based on their 5-digit postcode using Quantum GIS, version 2.4 (http://www.qgis.org/en/site/). Maps were created based on a Swedish 5-digit postcode vector layer obtained from "Statistics Sweden" (SCB), a Governmental agency producing all official statistics regarding Sweden (http://www.scb.se/).

Questionnaire data and ELISA results were compiled in Excel spreadsheets (Microsoft ${ }^{\odot}$ ) and then incorporated and analysed using SPSS ${ }^{\circledR}$ Statistics, version 22.0 (IBM, New York, NY, USA). The effect of management practices with regard to F. hepatica infection status was evaluated by bivariate and multivariate statistical methods. For logistic regression purposes, the ELISA results were simplified and only negative herds $(\mathrm{OD}<0.3)$ and positive herds $(\mathrm{OD}>0.3$, i.e. both weakly and highly F. hepatica-positive ones together) were used. The herd infection status based on the ELISA results (expressed as positive $=1$ or negative $=0$ ) was always the dependent variable, while management practices (Table 1) served as covariate variables. Bivariate correlation analysis was first carried out, followed by binomial logistic regression analysis for all variables, including Omnibus Tests of Model Coefficients and the Hosmer and Lemeshow Test to express the predictive values. In the first regression modelling, all variables were analysed together. Second, variables were divided into subcategories and six models were obtained: (i) herd type; (ii) specific management practices for cows; (iii) specific management practices for heifers; (iv) length of grazing period for cows and heifers; (v) herd size and milk production; and (vi) reduction in milk production and meat inspection remarks. Third, significant variables from bivariate correlation and the six regression models were selected and included in the final model. Associations between seropositivity and the presence of a patent liver fluke infection (code 79/80) and/or in combination with pathological liver damage observed at slaughter in animals from the same herds during meat inspections for the three previous years (code 83/84) were also examined by cross-tabulation in a contingency analysis in Graph Pad Prism 5.02 (GraphPad Software; CA, USA).

\section{Results}

A total of 107 herds (25\% prevalence, $95 \%$ confidence interval $=21 \%$ to $29 \%$ ) tested positive for F. hepatica antibodies. Thirty-one of these $(29 \%)$ were highly positive with antibody levels indicating poten- tial production loss. The majority of the highly positive herds $(n=92)$ were located in south-west Sweden, in the counties of Skåne and Västra Götaland, whereas only 15 positive herds were from the east coast of Sweden (Fig. 1). A total of 176 farmers (41\%), homogeneously distributed throughout the study area, responded to the questionnaire (Fig. 1). However, the questions were not always completely answered; 337 of the 7,216 questions $(4.7 \%)$ were left without response. In total, 129 herds ( $73 \%)$ were kept solely for milk production and the remaining 47 herds for combined milk and beef production. Among 43 positive herds, at farms that also responded to the questionnaire, $31(72 \%)$ were purely dairy cattle with the herd size varying between 15 and 640 animals (Fig. 2). The ratio of conventional to organic farms was 5:1 (Fig. 3). Furthermore, all cows and heifers had outdoor access for several months during the grazing period, a statutory requirement in Sweden.

In the bivariate correlation analysis, the length of the grazing period for heifers $(\mathrm{R}=0.244 ; \mathrm{P}=0.002)$ was positively correlated with $F$. hepatica seropositivity in BTM seropositivity. A weak, non-significant correlation was observed for the length of grazing period for cows $(\mathrm{R}=0.136 ; \mathrm{P}=0.077)$, herd size $(\mathrm{R}=0.123 ; \mathrm{P}=0.142)$ and mowing of cow pasture $(\mathrm{R}=0.123 ; \mathrm{P}=0.109)$. The multivariate regression logistic model for all variables did not fit, and its predictive value was low (Omnibus Tests of Model Coefficients $=3.158, \mathrm{P}=0.676$; Hosmer and Lemeshow Test $=5.312, \mathrm{P}=0.724)$. Of the six models for specific categories, only the length of grazing period for cows and heifers (model IV) was close to statistical significance (Omnibus Tests of Model Coefficients $=8.351 ; \quad \mathrm{P}=0.080 ; \quad$ Hosmer and Lemeshow Test $=1.140 ; \mathrm{P}=0.951)$. According to this model, the length of the grazing period for heifers was a significant positive predictor of $F$. hepatica seropositivity as expressed by the exponent of regression coefficient $(\operatorname{Exp}(B)=2.709 ; 95 \%$ confidence interval of $\operatorname{Exp}$ $(B)=1.170-6.273)$. For the final model, four factors (length of grazing period for heifers, length of grazing period for cows, herd size, mowing of cow pasture), which were significant or close to significant in the initial bivariate correlations, were manually selected for further testing with multivariate analysis. According to the final model, length of the grazing period for heifers was the only significant predictor (Table 2). Mowing of cow pastures had also predictive potential but was not statistically significant $(\mathrm{P}=0.116)$.

No correlation was observed between meat inspection data and seropositivity, but there was an apparent difference between the proportion of seropositive and 


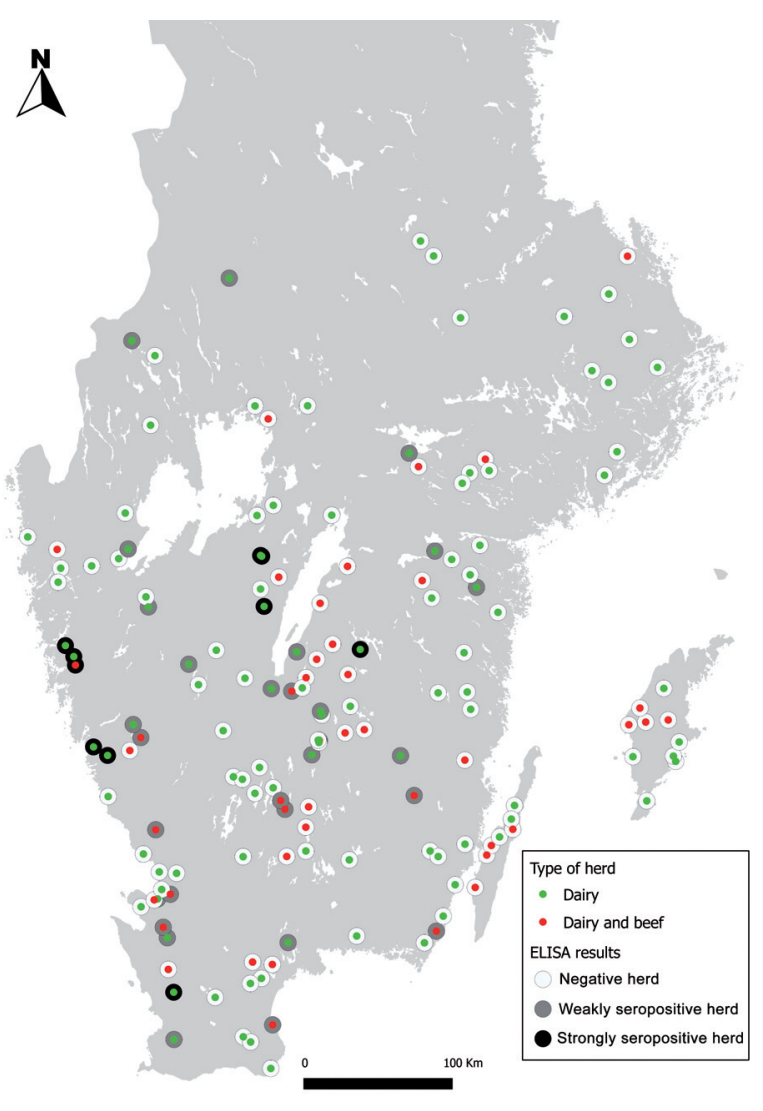

Fig. 2. Distribution of herd type (dairy or dairy and beef) and F. hepatica seropositive herds in Sweden in the farms that completed the questionnaire $(n=176)$.

seronegative herds for the categories "no remarks" and "liver fluke presence" (code 79/80) (Fig. 4). Contingency analysis revealed significant differences between groups $\left(\chi^{2}=21.2 ; \mathrm{P}<0.001\right)$. Of 71 herds with no remarks or unknown status at inspection, $12(17 \%)$ of the BTM samples were liver fluke-seropositive. In contrast, out of 105 herds where the parasite was observed at slaughter, in combination with those, which had pathological liver changes, only 31 BTM samples $(30 \%)$ had antibodies to F. hepatica. The highest seroprevalence $(80 \%)$ among these groups was recorded in 45 herds with confirmed presence of liver flukes at slaughter and the second highest $(29 \%)$ in herds $(\mathrm{n}=31)$ where both liver flukes and liver damage were found.

\section{Discussion}

The overall level of F. hepatica seroprevalence in Sweden found in this study $(25 \%)$ is similar to, or somewhat lower than that reported for several other European countries, e.g. Belgium 37\% (Bennema et al., 2009), UK 48-72\% (Salimi-Bejestani et al., 2005; McCann et al., 2010), Portugal 11-42\% (Conceicao et

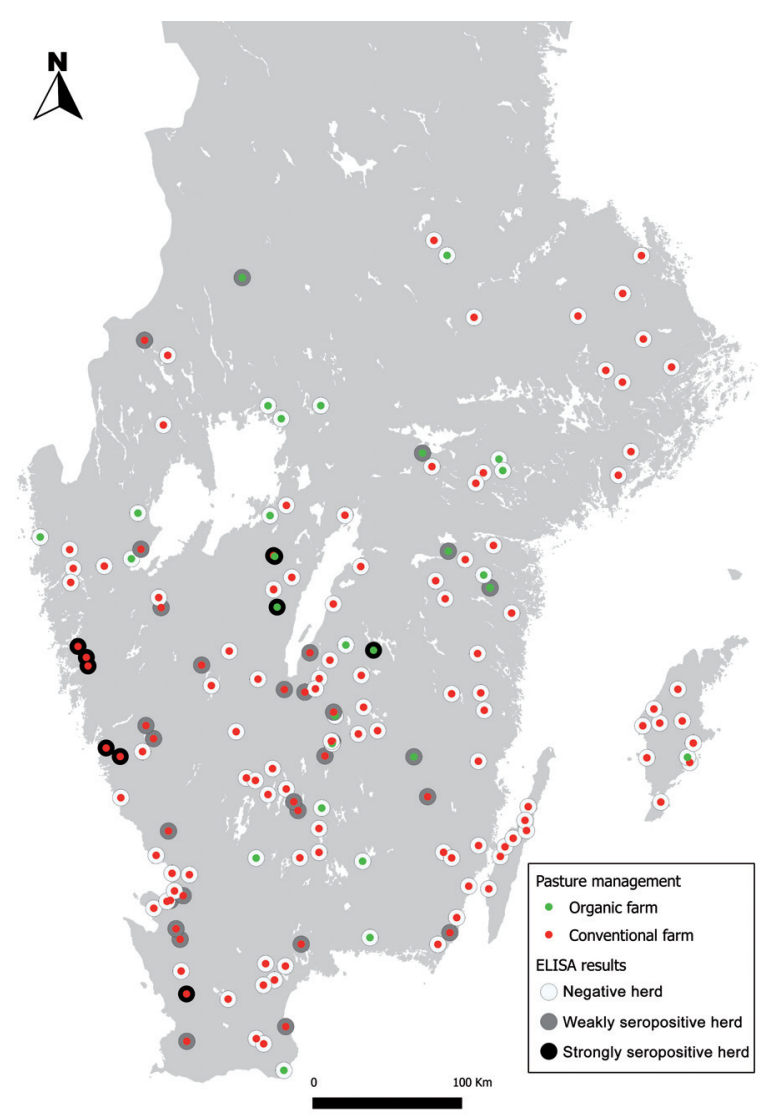

Fig. 3. Distribution of herd type production (organic or conventional) and F. hepatica seropositive herds in Sweden in the farms that completed the questionnaire $(\mathrm{n}=176)$.

al., 2004), Germany 24\% (Kuerpick et al., 2013) and Spain 20\% (Sanchez-Andrade et al., 2002). In contrast, it is much higher than that reported in a previous Swedish study in 2008 , when only $7 \%$ of 205 herds were infected (Höglund et al., 2010). However, these and several other studies only covered a small region in each country, whereas the present investigation was region-wide and included approximately $9 \%$ of all dairy herds in Sweden at the time.

In the study year, the reported prevalence of F. hepatica infection based on meat inspection was only $9.8 \%$ in all cattle slaughtered in Sweden (König and Welling, 2013), while we found $25 \%$ seropositivity. Similar discrepancies between meat inspection data and serology screening were observed for beef cattle in Sweden in 2007 (Novobilský et al., submitted), where seroprevalence and abattoir prevalence were $10 \%$ and $3.5 \%$, respectively. Similar observations were reported from Switzerland, where infected livers were detected only in two-thirds of seropositive animals at abattoir inspection (Rapsch et al., 2006). Charlier et al. (2008) showed that only one third of F. hepatica infected livers was detected by standard meat inspection cuts, that 
Table 2. Final regression logistic model describing variations in herd seropositivity and four variables.

\begin{tabular}{|c|c|c|c|c|c|c|c|c|}
\hline \multirow[t]{2}{*}{ Variable } & \multirow[t]{2}{*}{$\mathrm{B}^{\mathrm{a}}$} & \multirow[t]{2}{*}{$\mathrm{SE}^{\mathrm{b}}$} & \multirow[t]{2}{*}{ Waldc } & \multirow[t]{2}{*}{$\mathrm{df}^{\mathrm{d}}$} & \multirow[t]{2}{*}{ Significance } & \multirow[t]{2}{*}{$\operatorname{Exp}(B)^{e}$} & \multicolumn{2}{|c|}{$95 \% \mathrm{CI}^{\mathrm{f}}$ of $\operatorname{Exp}(\mathrm{B})$} \\
\hline & & & & & & & Lower & Upper \\
\hline Length of grazing period for heifers & 0.739 & 0.353 & 4.388 & 1 & $0.036^{*}$ & 2.093 & 1.049 & 4.179 \\
\hline Length of grazing period for cows & 0.165 & 0.316 & 0.273 & 1 & 0.6011 & 1.180 & 0.635 & 2.193 \\
\hline Herd size (number of dairy cows) & -0.003 & 0.003 & 1.172 & 1 & 0.2789 & 0.997 & 0.991 & 1.003 \\
\hline Mowing of cow pasture & 0.407 & 0.259 & 2.475 & 1 & 0.1156 & 1.503 & 0.905 & 2.497 \\
\hline Constant & -6.207 & 2.088 & 8.837 & 1 & 0.0030 & 0.002 & & \\
\hline
\end{tabular}

${ }^{\mathrm{a}}$ Logistic regression coefficient; ${ }^{\mathrm{b}}$ Standard error; ${ }^{\mathrm{c}} \mathrm{Wald}$ test; ${ }^{\mathrm{d} D e g r e e s}$ of freedom; ${ }^{\mathrm{e}}$ Exponential of logistic regression coefficient; ${ }^{\mathrm{f} 95 \%}$ Confidence interval of logistic regression exponent.

\begin{tabular}{ccc}
\hline \multicolumn{3}{l}{ Omnibus Tests of Model Coefficients } \\
\hline$\chi^{2}$ & $\mathrm{df}$ & Signifacance \\
10.071 & 4.000 & 0.039 \\
\hline \multicolumn{2}{l}{ Hosmer and Lemeshow Test } & \\
\hline$\chi^{2}$ & $\mathrm{df}$ & Signifacance \\
3.914 & 8 & 0.865 \\
\hline Model summary & & \\
\hline-2 Log likelihood & Cox \& Snell R Square & Nagelkerke R Square \\
133,309 & 0.076 & 0.113 \\
\hline
\end{tabular}

include opening of the major bile duct. These observations, in combination with our findings, suggest that liver fluke infection is underdiagnosed at meat inspection for all cattle categories. This is further supported by the fact that the data from meat inspection reports did not always correlate with the BTM-ELISA results. There are several reasons for this. First, it has been demonstrated that $20-60 \%$ of animals in a herd must be infected to produce a positive result in BTM-ELISA

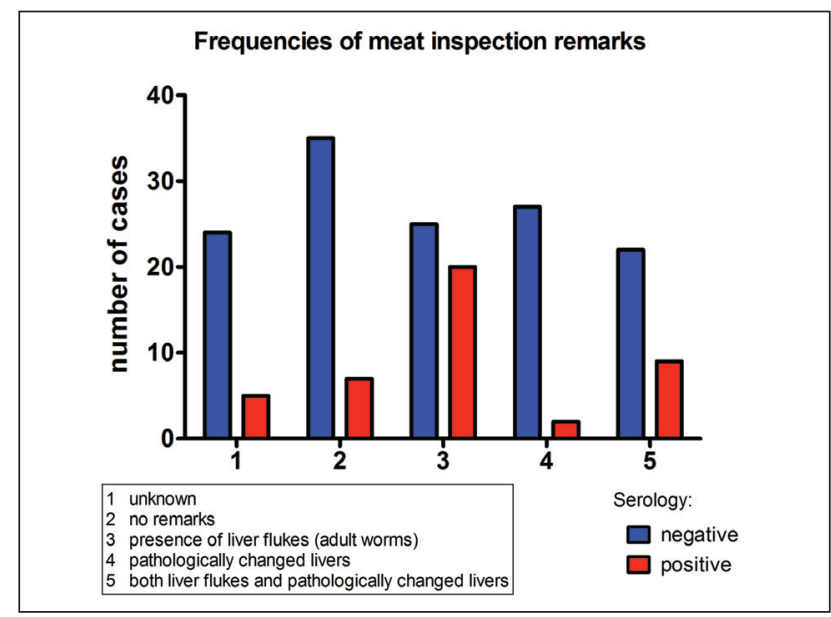

Fig. 4. Relationship between ELISA results for bulk tank milk (BTM) and fluke detection at meat inspection in dairy herds in the farms that completed the questionnaire $(n=176)$.
(Reichel et al., 2005; Duscher et al., 2011). Thus, the finding of seronegative herds with reported liver flukes at slaughter might be explained by the fact that the infection burden was low and that this minimum herd prevalence was not detectable by the ELISA-based BTM investigation. Secondly, although antibody levels remain high for several months (Phiri et al., 2006), data from abattoir inspections were obtained via the questionnaire and reflected the situation in the herd during the previous three years. Thus the datasets did not exactly match each other. We have to admit that meat inspection data in the study were obtained from farmers via the questionnaire, and meat inspection data can be affected depending of the level of communication between abattoir and farmer. However, abattoirs in Sweden (>100 slaughtered animals per day) usually give direct feedback to farmers about meat inspection results, which are protected by privacy policy.

The spatial distribution of liver fluke-positive herds in this study agrees with that observed for a serologic survey of Swedish beef cattle carried out in 2007 (Novobilský et al., submitted), where two main clusters were defined in south-west Sweden. Unlike in beef cattle (Novobilský et al., submitted), we detected one positive dairy herd on Gotland, verifying the presence of liver fluke on this large Baltic Sea island, which until now has been assumed to be free of this infection. Abattoir data from Gotland, however, show prevalence rates less than $0.1 \%$ (König and Welling, 2013). It would be worthwhile investigating how the spread of F. hepatica is influenced by movement of farm animals.

The final logistic regression model showed that the length of grazing period for heifers was the only significant F. hepatica predictor. This is reasonable, as animals with an extensive grazing season are likely to be more exposed to liver fluke cysts (metacercariae). In cows, however, there was no association between length of the grazing period and liver fluke seropositivity. This is not surprising, as dairy cows are generally kept on frequently re-seeded grass leys, where expo- 
sure to metacercariae is less likely to occur. Management factors such as herd size, mowing of pasture and proportion of grass in the diet are all predictors in Belgium (Bennema et al., 2011; Charlier et al., 2011). Our data suggest an association with mowing of pasture and herd size, but not at a significant level.

Most F. hepatica-seropositive BTM samples (72\%) originated from conventional herds kept only for milk production. Although intensive dairy production with improved pastures should, hypothetically, predict lower exposure than for beef cattle, this was not observed in our study. Furthermore, there was no difference between conventional and organic herds. This is not surprising as, by law, all cattle in Sweden must have outdoor access during the entire grazing season. This confirms previous findings of no significant differences between conventional and organic herds (Höglund et al., 2010). In comparison with sheep, the use of flukicides in dairy cattle production in Sweden is very limited, and there is currently no drug for use in lactating animals (König and Welling, 2013). Thus, flukicides are not in general used in lactating and dry cows in both conventional and organic herds.

A milder climate associated with increased rainfall and a longer grazing period on waterlogged soil have previously been shown to be beneficial to both the parasite and its intermediate host (Conceiçao et al., 2004). Changes in weather conditions are likely to give similar problems in Sweden. The parasite is likely to increase in areas where it already exists today and can also spread to adjacent areas that were not previously a suitable habitat. Therefore, a further increase in liver fluke prevalence might be expected in Sweden. It can be assumed that most dairy cows are less exposed to metacercariae than calves and/or heifers in Sweden, because they generally graze on marginal pastures favouring habitats of the intermediate snail host (Novobilský et al., 2014). However, F. hepatica causes chronic infection and as the number of lactations in Swedish dairy cows is now down to an average of 2.6 (Växa Sverige, 2013), it was not surprising that seropositivity is relatively high in lactating animals. However, further studies are required to determine whether this affects liver fluke epidemiology, milk production and opportunities for parasite control.

\section{Acknowledgements}

This study was supported by the 7th Framework Programme of the EU (GLOWORM, Project FP7-KBBE-2012-288975) and partly by the Swedish Foundation for Agricultural Research (contract no. H1350023).

\section{References}

Anonymous, 2012. Parasitology in 2020. Where will we stand? Available at http://ec.europa.eu/food/animal/diseases/strategy/ docs/agenda_28062013_4_en.pdf (accesse on January 2015).

Bennema SC, Ducheyne E, Vercruysse J, Claerebout E, Hendrickx G, Charlier J, 2011. Relative importance of management, meteorological and environmental factors in the spatial distribution of Fasciola hepatica in dairy cattle in a temperate climate zone. Int J Parasitol 41, 225-233.

Bennema SC, Vercruysse J, Claerebout E, Schnieder T, Strube K, Ducheyne E, Hendrickx G, Charlier J, 2009. The use of bulktank milk ELISAs to assess the spatial distribution of Fasciola hepatica, Ostertagia ostertagi and Dictyocaulus viviparus in dairy cattle in Flanders (Belgium). Vet Parasitol 165, 51-57.

Charlier J, Bennema, SC, Caron Y, Counotte M, Ducheyne E, Hendrickx G, Vercruysse J, 2011. Towards assessing fine-scale indicators for the spatial transmission risk of Fasciola hepatica in cattle. Geospat Health 5, 239-245.

Charlier J, De Meulemeester L, Claerebout E, Williams D, Vercruysse J, 2008. Qualitative and quantitative evaluation of coprological and serological techniques for the diagnosis of fasciolosis in cattle. Vet Parasitol 153, 44-51.

Charlier J, Duchateau L, Claerebout E, Williams D, Vercruysse J, 2007. Associations between anti-Fasciola hepatica antibody levels in bulk-tank milk samples and production parameters in dairy herds. Prev Vet Med 78, 57-66.

Charlier J, Vercruysse J, Morgan E, Van Dijk J, Williams, DJL, 2014. Recent advances in the diagnosis, impact on production and prediction of Fasciola hepatica in cattle. Parasitology 141, 326-335.

Conceiçao MAP, Durao RMB, Costa IMH, Castro A, Louza AC, Costa JC, 2004. Herd-level seroprevalence of fasciolosis in cattle in north central Portugal. Vet Parasitol 123, 93-103.

Duscher R, Duscher G, Hofer J, Tichy A, Prosl H, Joachim A, 2011. Fasciola hepatica - Monitoring the milky way? The use of tank milk for liver fluke monitoring in dairy herds as base for treatment strategies. Vet Parasitol 178, 273-278.

Forbes AB, Charlier J, 2006. Bulk milk ELISAs for quantitative estimates of parasite infection. Cattle Pract 14, 167-173.

Höglund J, Dahlström F, Engström A, Hessle A, Jakubek EB, Schnieder T, Strube C, Sollenberg S, 2010. Antibodies to major pasture borne helminth infections in bulk-tank milk samples from organic and nearby conventional dairy herds in southcentral Sweden. Vet Parasitol 171, 293-299.

Höglund J, Engström A, Morrison DA, Mattsson JG, 2004. Genetic diversity assessed by amplified fragment length polymorphism analysis of the parasitic nematode Dictyocaulus viviparus the lungworm of cattle. Int J Parasitol 34, 475-484.

König U, Welling V, 2013. Stora Leverflundror. Svenska Djurhälsovården, Uppsala, Sweden.

Kuerpick B, Conraths FJ, Staubach C, Frohlich A, Schnieder T, 
Strube C, 2013. Seroprevalence and GIS-supported risk factor analysis of Fasciola hepatica infections in dairy herds in Germany. Parasitololgy 140, 1051-1060.

McCann CM, Baylis M, Williams DJL, 2010. Seroprevalence and spatial distribution of Fasciola hepatica-infected dairy herds in England and Wales. Vet Rec 166, 612-617.

Mezo M, Gonzalez-Warleta M, Castro-Hermida JA, Muino L, Ubeira FM, 2011. Association between anti-F. hepatica antibody levels in milk and production losses in dairy cows. Vet Parasitol 180, 237-242.

Novobilský A, Engström A, Sollenberg S, Gustafsson K, Morrison DA, Höglund J, 2014. Transmission patterns of Fasciola hepatica to ruminants in Sweden. Vet Parasitol 203, 276-286.

Novobilský A, Novák J, Björkman C, Höglund J, submitted. Impact of meteorological and environmental factors on the spatial distribution of Fasciola hepatica in beef cattle herds in Sweden. BMC Vet Res, in press.

Phiri IK, Phiri AM, Harrison LJS, 2006. Serum antibody isotype responses of Fasciola-infected sheep and cattle to excretory and secretory products of Fasciola species. Vet Parasitol 141, 234-242.

Rapsch C, Schweizer G, Grimm F, Kohler L, Bauer C, Deplazes P, Braun U, Torgerson PR, 2006. Estimating the true prevalence of Fasciola hepatica in cattle slaughtered in Switzerland in the absence of an absolute diagnostic test. Int J Parasitol 36,
1153-1158.

Reichel MP, Vanhoff K, Baxter B, 2005. Performance characteristics of an enzyme-linked immunosorbent assay performed in milk for the detection of liver fluke (Fasciola hepatica) infection in cattle. Vet Parasitol 129, 61-66.

Salimi-Bejestani MR, Daniel R, Cripps P, Felstead S, Williams DJL, 2007. Evaluation of an enzyme-linked immunosorbent assay for detection of antibodies to Fasciola hepatica in milk. Vet Parasitol 149, 290-293.

Salimi-Bejestani MR, Daniel RG, Felstead SM, Cripps PJ, Mahmoody H, Williams DJL, 2005. Prevalence of Fasciola hepatica in dairy herds in England and Wales measured with an ELISA applied to bulk-tank milk. Vet Rec 156, 729-731.

Sanchez-Andrade R, Paz-Silva A, Suárez JL, Panadero R, Pedreira J, López C, Díez-Baños P, Morrondo P, 2002. Influence of age and breed on natural bovine fasciolosis in an endemic area (Galicia, NW Spain). Vet Res Commun 26, 361-370.

Swedish Board of Agriculture, 2012. Available at: http://www.jordbruksverket.se/webdav/files/SJV/Amnesomrad en/Statistik\%2C\%20fakta/Husdjur/JO20/JO20SM1201/JO20 SM1201_kommentarer.htm (accessed on January 2015).

Växa Sverige, 2013. Cattle Statistics. Växa Sverige, Uppsala, Sweden.

Vercruysse J, Claerebout E, 2001. Treatment vs non-treatment of helminth infections in cattle: defining the threshold. Vet Parasitol 98, 195-214. 